\title{
Dietary Patterns and Colon Cancer Risk in Whites and African Americans in the North Carolina Colon Cancer Study
}

\author{
Jessie A. Satia, \\ Department of Nutrition, Schools of Public Health and Medicine, Department of Epidemiology, \\ Gillings School of Global Public Health, and Center for Gastrointestinal Biology and Disease, \\ School of Medicine, University of North Carolina at Chapel Hill, USA \\ Marilyn Tseng, \\ Division of Population Science, Fox Chase Cancer Center, Philadelphia, Pennsylvania, USA \\ Joseph A. Galanko, \\ Center for Gastrointestinal Biology and Disease, School of Medicine, University of North Carolina \\ at Chapel Hill, USA \\ Christopher Martin, and \\ Center for Gastrointestinal Biology and Disease, School of Medicine, University of North Carolina \\ at Chapel Hill, USA

\section{Robert S. Sandler} \\ Department of Epidemiology, Gillings School of Global Public Health and School of Medicine, and \\ Center for Gastrointestinal Biology and Disease, School of Medicine, University of North Carolina \\ at Chapel Hill, USA
}

\section{Abstract}

\begin{abstract}
We examined associations of dietary patterns with colon cancer risk in African Americans and Whites from a case-control study in North Carolina. Incident colon cancer cases, 40 to $80 \mathrm{yr}(n=$ 636), and matched controls $(n=1,042)$ were interviewed in person to elicit information on potential colon cancer risk factors. A validated food frequency questionnaire adapted to include regional foods captured diet over the year prior to diagnosis (cases) or interview date (controls). Three meaningful intake patterns were identified in both Whites and African Americans: "Western-Southern," "fruit-vegetable," and "metropolitan." Compared to the Western-Southern pattern, the fruit-vegetable and metropolitan patterns were associated with more healthful dietary behaviors (e.g., higher vegetable intake and lower red meat consumption), and demographic/ lifestyle characteristics typically correlated with low colon cancer risk, for example, lower BMI, higher education, and higher NSAID use. The fruit-vegetable pattern was significantly inversely associated with colon cancer risk in Whites $(\mathrm{OR}=0.4,95 \% \mathrm{CI}=0.3-0.6)$ and the metropolitan pattern with a nonsignificant $30 \%$ risk reduction in both Whites and African Americans after adjustment for education. The Western-Southern pattern was not associated with colon cancer risk. These findings may explain some of the racial differences in colon cancer incidence and
\end{abstract}


underscore the importance of examining diet-cancer associations in different population subgroups.

\section{INTRODUCTION}

Colon cancer is the third leading cause of cancer incidence and mortality in the United States (1), and one of the most common neoplasms in developed countries (2). The American Cancer Society estimates that in the year 2008, 108,070 new cases will be diagnosed, and 49,960 persons will die from colon cancer in the United States (1). Colon cancer incidence and mortality vary markedly by race and ethnicity; specifically, African Americans have the highest incidence and mortality rates among all U.S. racial/ethnic groups. Colon and rectal cancer incidence rates for 1999-2003 for African American males and females were 70.2 and 53.5 per 100,000, respectively; corresponding rates for Whites were 63.7 and 45.9 per 100,000, respectively $(3,4)$. In North Carolina, the patterns are similar; for the years 2000-2003, colon and rectal cancer incidence rates for Whites were 46.1 per 100,000 (54.7 males, 39.3 females), and 55.9 per 100,000 (65.9 males, 49.5 females) for African Americans (3).

Reasons for racial/ethnic differences in colon cancer risk remain poorly understood. Although differences in behavioral, socioeconomic, cultural, and health care access related issues are likely contributors, they do not fully account for the disparities $(1,5-8)$. Also, the increase in colon cancer incidence in African Americans does not seem to be attributable to higher rates of screening and early detection (5-8). Differences in hereditary susceptibility factors and related gene-environment interactions are likely explanations that are currently being studied. In addition, it is important to identify salient lifestyle and behavioral factors that are potentially modifiable and that may decrease colon cancer incidence in both African Americans and Whites.

Variations in colon cancer incidence with geography and migration strongly implicate environmental factors and/or modifiable lifestyle habits as important determinants of colon cancer risk (6-10). Although physical activity and tobacco smoking are examples of such characteristics, the predominant factor is thought to be diet. Numerous studies have shown that dietary behavior impacts an individual's risk of developing colon cancer, and diet has long been regarded as the most important lifestyle risk factor for colon cancer (6-10). In fact, it has been estimated that $12 \%$ of colon cancer is attributable to consumption of a Western-style diet (10). However, although there have been many diet and colon cancer studies, the impact of specific dietary factors on colon carcinogenesis remains unresolved, particularly because the presumed protective effects of fruits, vegetables, and fiber have been recently challenged by well-designed prospective trials $(11,12)$. Furthermore, associations of diet with colon cancer risk have been rarely examined in African Americans or in population-based studies with an adequate number of African American participants.

In light of conflicting results from studies on nutrient or food group intakes, there is growing interest in examining dietary patterns $(13,14)$. Dietary pattern analysis reflects both nutrient/ food group intakes and the types of foods that tend to be consumed together in the usual diet -a perspective that is typically lost in analyses focusing on single dietary factors-and may 
therefore provide additional insights into the diet and colon cancer relationship in a number of ways: 1) it takes into account the combined (and possibly synergistic) effects of foods, 2) there are likely racial/ethnic differences in dietary patterns that may contribute to variations in risk, 3) humans consume meals that include a variety of foods and not individual nutrients, and 4) patterns are more amenable to translation into dietary recommendations. Thus, the dietary pattern approach may be most useful for elucidating these complex relationships and may provide considerably more insight beyond the examination of individual foods and nutrients $(13,14)$. To our knowledge, there are no published studies of dietary patterns and colon cancer risk in African Americans.

We have previously examined associations of total energy and macronutrients, micronutrients, and food groups in relation to colon cancer risk in the present study population. The objectives of this report are to investigate the role of dietary patterns on colon cancer risk and to determine whether the effect of these intake patterns differ by race in a large case-control study in North Carolina with comparable numbers of African American and White cases and controls. Our study contributes to the existing body of literature by 1) describing dietary patterns by racial group (Whites and African Americans) in a large sample of colon cancer cases and controls and 2) presenting associations of dietary patterns with colon cancer risk stratified by race in a Southern population sample.

\section{MATERIALS AND METHODS}

\section{Study Design}

The North Carolina Colon Cancer Study (NCCCS) is a population-based, case-control study of colon cancer in North Carolina. Study participants were from 33 counties in the central portion of North Carolina, an area that includes rural, suburban, and urban counties with a diverse socioeconomic mix of African Americans and Whites. The study was approved by the Institutional Review Board at the University of North Carolina School of Medicine and by equivalent committees at the collaborating hospitals.

\section{Study Population}

Cases and controls were selected using a randomized recruitment approach to achieve approximate frequency matching on age, sex, and racial group and to achieve a racial group ratio optimized for statistical efficiency $(15,16)$. African American cases were oversampled at a ratio of approximately 3:1. Participants were offered a $\$ 25$ incentive to take part in the study.

Cases-Persons with a first diagnosis of histologically confirmed invasive adenocarcinoma of the colon between October 1, 1996 and September 30, 2000 were identified through the rapid ascertainment system of the North Carolina Central Cancer Registry (17). Other eligibility criteria included age 40 to $80 \mathrm{yr}$ at the time of diagnosis, residence in the 33county study area in North Carolina, ability to give informed consent and complete the interview, a North Carolina driver's license or identification card if under age 65 (because controls under age 65 were sampled from driver's license rosters), and permission to contact 
from the primary physician. Interviews with eligible and consenting patients were generally conducted within 5 mo of surgery.

Controls-The noninstitutionalized population-based controls were selected from 2 sources: North Carolina Division of Motor Vehicle records for cases under the age of 65 and from the Center for Medicare and Medicaid Services for cases $65 \mathrm{yr}$ or older. These listings were used to randomly select potential controls within the same 5-yr age group-defined, sexdefined, and racial group-defined strata. Those identified as eligible controls were contacted in a similar fashion to the cases to schedule in-person interviews.

Completed interviews were obtained from 1,691 participants. The overall study cooperation rate [interviewed/(interviewed + refused)] was $84 \%$ for cases and $63 \%$ for controls, whereas the response rate (interviewed/eligible) was $72 \%$ for cases and $61 \%$ for controls. For both cases and controls, the cooperation and response rates were slightly higher for Whites than for African Americans (18).

\section{Data Collection}

Data were collected in person by trained nurse interviewers at the participant's home or, occasionally, at another convenient location. The questionnaire collected detailed information on several factors that might relate to colon cancer including dietary and lifestyle factors and medical history. The referent period for the interview was the year before diagnosis (cases) or interview date (controls).

Dietary Intake-Diet was assessed using a modified version of a previously validated 100item semiquantitative Block food frequency questionnaire (FFQ) that was adapted to capture regional dietary practices by adding 29 foods commonly consumed in North Carolina such as cooked greens, black-eyed peas, fried shellfish, hushpuppies, grits, and cobblers (19). In the present study, respondents were asked to estimate their usual frequency of consumption of various foods and typical portion sizes for the year prior to diagnosis (cases) or the year preceding the interview date (controls). Each food item had 9 options for frequency (ranging from "never or less than once per month" to " $2+$ times per day") and 3 options for portion size. The FFQ also included adjustment questions on types of foods used in cooking and preparation techniques and questions relating to restaurant eating, consumption of low-fat foods, fortified beverages, and fats used in cooking. Food groups and nutrient intakes were generated by an analysis program provided by the National Cancer Institute (20).

Identification of Dietary Patterns-Patterns of food intake were identified by principal components analysis (PCA) using frequency responses to the dietary questionnaire $(21,22)$. To explore differences in dietary patterns by race, we conducted analyses in Whites and African Americans separately. For each of the two racial groups, individuals were randomly placed into one of two equally sized groups, or split samples, in order to confirm reproducibility of the principal components identified. For the first split sample, a matrix of correlations among frequency of consumption for the questionnaire food items was constructed and entered in the PCA. Extraction of principal components was followed by orthogonal rotation of retained components to allow for interpretability $(21,22)$. The number 
of components to retain for rotation was based on examination of scree plots and interpretability of the components (22). The analysis was repeated in the second split sample to confirm reproducibility of results. Cronbach's alpha coefficient (23) was used to evaluate internal consistency for each component retained, with a coefficient alpha of $\searrow 0.70$ generally indicating acceptable reliability (24).

\section{Other Participant Characteristics}

Data were collected on several demographic, lifestyle, and behavioral characteristics including age, sex, education, race, physical activity, vitamin/mineral supplement use, smoking history, use of nonsteroidal anti-inflammatory drugs (NSAIDs) over the last $5 \mathrm{yr}$, and first-degree family history of colon cancer. Using a standardized protocol, trained staff measured height and weight at the in-person interview. Height and weight were used to compute body mass index as weight (in kilograms) divided by height (in meters) squared. Body mass index (BMI) was further categorized as normal, 18.5-24.9; overweight, 25.029.9; and obese, 330.0 (25). Participants in the underweight category with body mass indexes of less than 18.5 and those with body mass indexes of more than 50 were not included in these analyses $(n=36)$, as they comprised a very small percentage $(<2 \%)$ of the analytical sample. Physical activity was measured in metabolic equivalent task (MET) $\mathrm{min}$ /day for combined occupational, nonoccupational, and nonwork/weekend activities (including duration, frequency, and intensity) using a modified version of a validated 7-day physical activity recall $(26,27)$.

\section{Statistical Analysis}

Descriptive statistics (raw means, SDs, and percentages) stratified by race (White and African American) and case/control status were used to describe the demographic/lifestyle characteristics and dietary intakes of study participants (Table 1). A component score was calculated for each dietary pattern for each individual to represent the individual's level of intake for the pattern (Table 2 and Table 3). Scores were calculated by taking the unweighted sum of standardized frequencies of intake for the foods with meaningful loadings ( $\left(\searrow_{0} .20\right.$ ) for only that pattern. To examine associations of participant characteristics with the dietary patterns among controls (tertile 1 vs. tertile 3 ), frequency and percentages were compared for categorical variables via a $\chi^{2}$ test, and least square means were computed for continuous variables using linear regression models. Dietary variables were adjusted for total energy intake using the residual method (28).

We calculated odds ratios (ORs) and 95\% confidence intervals (CIs) from unconditional logistic regression models to ascertain associations of the dietary patterns (in tertiles) with colon cancer risk. Offset terms were included in all models to correct for randomized recruitment sampling fractions $(15,16)$ and allow estimation of unbiased ORs. This was necessary because we conditioned recruitment on age, sex, and race in addition to disease status; thus, the ORs without the offset term will be biased compared to a traditional design in which recruitment is conditioned on disease status alone. Cut points for tertiles of the dietary patterns were determined based on the distributions among controls. All participant characteristics in Table 1 (except current BMI) were evaluated as potential confounding factors; covariate inclusion was based on whether there was a $15 \%$ or greater alteration in 
the parameter coefficient of interest. Two types of logistic regression models were run: a minimally adjusted model with age, sex, total energy, and the offset term; and a fully adjusted model that included the 4 variables listed above and other variables determined to be confounders. A $P$ value for linear trend for each of these models was found by rerunning the model while including the tertile term in the model as a continuous variable. Statistical tests were 2-sided, and $P$ values less than 0.05 were considered statistically significant. All analyses were performed using SAS System 9.1 (SAS Institute Inc., Cary, NC).

\section{RESULTS}

Table 1 gives the characteristics of study participants by race and case-control status. The study sample included 636 cases (290 African Americans) and 1,042 controls (432 African Americans). White cases were slightly older than African American cases, and African American cases were more likely to be female. Compared to Whites, African Americans were also more likely to have less than high school education and be obese (both currently and $1 \mathrm{yr}$ ago), although the differences were not statistically significant. For both racial groups, there were no statistically significant differences between cases and controls by educational level, physical activity (MET min/day), or smoking history; however, the majority of White cases were former smokers (52\%), whereas African American cases were more often never smokers (47\%). Although cases and controls did not differ by current BMI, mean BMI values from the year prior to diagnosis suggested that cases had lost weight (28.4 vs. $27.3 \mathrm{~kg} / \mathrm{m}^{2}$ for Whites and 30.5 vs. $28.8 \mathrm{~kg} / \mathrm{m}^{2}$ for African Americans). Finally, cases were more likely than controls to have a family history of colon cancer, and they were less likely to have used NSAIDs regularly over the previous $5 \mathrm{yr}$ or to have used vitamin/ mineral supplements during the preceding year (all $P$ s $<0.05$ ).

We identified three meaningful intake patterns in Whites (Table 2) and three similar patterns in African Americans (Table 3): 1) a "Western-Southern" pattern with high loadings for red meats, fried chicken and fish, eggs, French fries, cheese dishes, white bread, and sweets; 2) a "fruit-vegetable" pattern with high loadings for various fruits, vegetables, and legumes such as collards, green beans, and yams, and cereals; and 3) a "metropolitan" pattern characterized by intake of salad and seafood, as well as, among Whites, Mexican foods, pastas, chicken, turkey, veal, and lamb and in African Americans, cruciferous vegetables, pasta salad, alfalfa sprouts, and yogurt.

To place these dietary patterns in context, we examined the distributions of selected demographic, lifestyle, and behavioral characteristics across pattern tertiles among White and African American controls (Table 4 and Table 5). As shown in Table 4, in Whites, those with high intake of the Western-Southern pattern were more likely to be male, to have no higher than a high school education, and to smoke; were less likely to use vitamin/mineral supplements; and reported higher intakes of red meat, refined carbohydrates, vegetables, energy, and total fat but lower intakes of alcohol, fruits, fiber, vitamin C, folate, and calcium. Those with high intake of the fruit-vegetable pattern were older; were more likely to be female, to have a college degree, and to use NSAIDs and vitamin or mineral supplements; had lower BMI; were less likely to smoke; and had higher intake of dairy, fruits, vegetables, fiber, $\beta$-carotene, vitamins $\mathrm{C}$ and $\mathrm{E}$, folate, and calcium but lower intake 
of red meats and total fat. Finally, White participants with high intake of the metropolitan pattern were younger, better educated, and more physically active; were less likely to have a family history of colon cancer; and had higher intake of alcohol, dairy, refined carbohydrates, fruits, vegetables, energy, fiber, vitamin $\mathrm{C}$, folate, and calcium but lower intake of total fat. Although dietary correlates of the fruit-vegetable and metropolitan patterns were similar with respect to their associations with higher intake of dairy, fruits, and vegetables and lower intake of total fat, they differed in other ways. Notably, the fruitvegetable pattern was additionally associated with higher intake of $\beta$-carotene and vitamin $E$ but lower intake of red meat, whereas the metropolitan pattern was associated with higher intake of refined carbohydrates, energy, and alcohol.

Among African Americans, correlates of high intake of the Western-Southern pattern were generally similar to those identified in Whites except that the pattern was not associated with smoking status and was associated with higher dairy intake (Table 5). For the fruit-vegetable pattern, African Americans with high intake were older and less likely to smoke. Unlike Whites, they had higher intake of all the food groups examined, including red meat, as well as of energy, fiber, $\beta$-carotene, vitamin C, folate, and calcium; but they reported lower alcohol consumption. Finally, only high level of education emerged as a significant positive demographic correlate of the metropolitan pattern in African Americans. Dietary correlates of this pattern were generally similar to those identified for Whites except that alcohol intake was inversely rather than positively associated with metropolitan pattern intake in African Americans. Also, as in Whites, whereas the fruit-vegetable and metropolitan patterns in African Americans shared common dietary correlates, including dairy, refined carbohydrates, vegetables, energy, fiber, $\beta$-carotene, vitamin $\mathrm{C}$, folate, and calcium and an inverse correlation with alcohol intake, they differed in other notable ways: The fruitvegetable pattern in African Americans was additionally associated with higher intake of red meat and fruits, whereas the metropolitan pattern was associated with higher intake of vitamin $\mathrm{E}$ and lower intake of fat.

Associations of the three dietary patterns with colon cancer risk are given in Table 6. In Whites, whereas the Western-Southern pattern was not associated with risk, high intake of the fruit-vegetable dietary pattern was significantly, inversely associated with risk for colon cancer (third vs. first tertile $\mathrm{OR}=0.4,95 \% \mathrm{CI}=0.3-0.6$; trend $P=0.0001$ ). High intake of the metropolitan pattern was also inversely related to colon cancer risk, although adjustment for level of education attenuated the estimate to marginal significance (third vs. first tertile $\mathrm{OR}=0.7,95 \% \mathrm{CI}=0.5-1.0$; trend $P=0.08$ ).

In African Americans, neither the Western-Southern pattern nor the fruit-vegetable pattern was associated with colon cancer risk (Table 7). The metropolitan pattern was inversely related to risk to a magnitude similar as that observed for Whites; however, adjustment for level of education attenuated OR estimates (third vs. first tertile $\mathrm{OR}=0.7,95 \% \mathrm{CI}=0.5-$ 1.1 ; trend $P=0.11$ ). 


\section{DISCUSSION}

In this study of dietary patterns and colon cancer risk in Whites and African Americans in North Carolina, we identified 3 dietary patterns: Western-Southern, fruit-vegetable, and metropolitan. Although the fruit-vegetable and metropolitan shared many similar demographic, lifestyle, behavioral, and dietary correlates in both racial groups, there were some noteworthy differences. Finally, only the fruit-vegetable pattern was significantly (inversely) associated with risk for colon cancer in Whites after control for covariates (specifically, level of education); none of the patterns were significantly associated with risk in African Americans in fully adjusted models.

The food items that loaded highly on each of the 3 intake patterns that we identified were remarkably similar overall in Whites and African Americans, leading us to use the same pattern names in both racial groups despite some differences. Our Western-Southern and fruit-vegetable patterns resemble patterns that have often been called the "Western" and "prudent/healthy" patterns in other studies (29-32). We also identified a dietary pattern characterized by higher intakes of salad and seafood as well as other food items that differed by race, which we termed metropolitan.

Associations of participant characteristics with the dietary patterns revealed some interesting similarities across patterns and differences by race. Demographic correlates of the fruitvegetable and metropolitan patterns were generally similar for both Whites and African Americans and were factors that are typically associated with lower cancer risk such as higher education, high physical activity, higher vitamin/mineral supplement and NSAID use, lower BMI, and low smoking. In both Whites and African Americans, however, whereas the fruit-vegetable pattern was associated with older age, the metropolitan pattern was associated with younger age. The dietary factors associated with the two patterns also differed somewhat. Among Whites, the metropolitan pattern was, unlike the fruit-vegetable pattern, additionally associated with higher intake of refined carbohydrates, total energy, and alcohol, likely because of its inclusion of carbohydrate-rich foods such as Mexican dishes and pasta. Among African Americans, whereas the fruit-vegetable pattern was associated with higher intake of red meat, the metropolitan pattern correlated with lower fat consumption. The Western-Southern pattern was the least healthy of the dietary patterns, both with regards to its constituent foods (e.g., fried chicken, red meats, French fries, sweets, etc.) and its demographic, lifestyle, and dietary correlates including lower education, higher smoking, low use of vitamin/mineral supplements; higher intakes of total energy, red meat, refined carbohydrates; and lower consumption of vitamin $\mathrm{C}$, folate, and calcium.

It is worth noting that African Americans reported higher intakes of most food groups and nutrients, except alcohol, even among those in the healthier dietary patterns. Also, although Whites and African Americans shared common dietary correlates for the fruit-vegetable and metropolitan patterns such as dairy, refined carbohydrates, vegetables, vitamin $\mathrm{C}$, and calcium, African Americans in the fruit-vegetable pattern reported higher intakes of red meat and fruits, whereas those in the metropolitan pattern consumed less fat and more vitamin E. Although energy intakes for Whites and African Americans in this study sample were comparable (18), in several other reports of both persons with cancer and disease-free 
individuals, African Americans have generally been found to have higher total energy intakes compared to their White counterparts $(33,34)$. Also, similar to our findings, other studies have reported lower alcohol $(33-35)$ and higher red meat consumption $(33,34,36)$ in African Americans compared to Whites.

Previous studies on dietary patterns and colon cancer have generally reported that the Western pattern is associated with statistically significant elevated risk, whereas findings for a prudent pattern have been less consistent $(29-32,37,38)$. In our sample, it is rather surprising that the Western-Southern pattern was not significantly associated with risk for colon cancer given that it includes dietary factors such as high total energy, high fat, and red meat that have been implicated in elevated colon cancer risk $(6,7,10,39)$ including in this study sample (18). Nonetheless, we note that in our sample, persons who scored high on this pattern had other behaviors that are associated with lower risk including high vegetable consumption (Whites) and nonsmoking (African Americans). In contrast to other studies that have identified a prudent or "healthy" dietary pattern (29-32), our fruit-vegetable pattern was robustly significantly associated with lower risk in Whites $(\mathrm{OR}=0.4,95 \% \mathrm{CI}=$ 0.3-0.6); however, there was no association in African Americans. The result for Whites is not unexpected, as several investigations, including the present study (39), have found that high vegetable consumption correlates with reduced risk for colon cancer including one using principal components-based patterns (30). It is unclear why this intake pattern was not associated with reduced risk in African Americans in our sample; possibly the fact that African Americans who were represented in this pattern were older and had higher intakes of other dietary risk factors, such as red meat and total energy, moderated the possible benefit of the fruits, vegetables, and legumes. Associations of the metropolitan pattern with colon cancer risk were similar in both Whites and African Americans, although the $30 \%$ risk reduction was no longer statistically significant after adjustment for educational level.

We note that these findings are of importance because they indicate that dietary patterns that are apparently similar across populations might have differential associations with disease (e.g., colon cancer) because of differences in context. For example, whereas the fruitvegetable pattern was associated with reduced risk in Whites, it was not protective in African Americans, possibly because of its association with higher red meat intake in that subgroup. Similarly, whereas previous studies have reported elevated colon cancer risk with a Western pattern, we found no such increased risk for the Western-Southern pattern in the present analyses, suggesting that in the South, perhaps deleterious effects of a Western diet may be countered by aspects of a Southern diet (such as higher vegetable intake). Overall, the results reported here point to a need to describe context-specific factors that may produce variability in the effects of apparently similar dietary patterns in different population subgroups. Such future efforts would improve our understanding of the effects of different socially determined eating habits, help explain inconsistencies observed across studies, and lead to more relevant public health messages that take context into consideration.

The strengths of our study include its population-based study design, relatively large size, the use of rapid case ascertainment, and the fact that data were collected with a detailed interviewer-administered questionnaire, which permitted the collection of comprehensive 
information on diet and other colon cancer risk factors, thereby reducing the potential for misclassification (40). Most notably, to our knowledge, it is the first study of dietary patterns and colon cancer risk in African Americans and the first to explore these associations in a relatively large sample of both Whites and African Americans. Importantly, our findings of racial differences in the 1) foods that constitute each pattern; 2) demographic, lifestyle, behavioral, and dietary correlates of the intake patterns; and 3) associations with colon cancer risk highlight the importance of examining these issues separately in different population subgroups.

We also acknowledge some limitations. First, as with other case-control studies, there is the possibility of selection and recall bias. Specifically, selection bias is a concern due to the lower participation rates of controls, and differential recall between cases and controls is a possibility because exposure information was collected after diagnosis of the disease; in particular, cases may recall dietary exposures differently from controls because of the presence of their illness and/or symptoms (40). Nonetheless, we made every effort to reduce bias; for example, we limited most of our exposure information to $1 \mathrm{yr}$ prior to diagnosis for cases or the year prior to the interview for controls, and exposure information was collected as soon as possible after diagnosis. Our response rates were also comparable to previous population-based case control studies (41-43). Second, FFQs are prone to measurement error and bias (44-47); however, replication across split samples and high coefficient values for Cronbach's alpha indicate good reproducibility and internal reliability for the patterns identified. Third, the 1-yr referent period on which exposure data (including dietary intake) were based would not be appropriate to correctly determine associations if remote diet (i.e., 5-10 yr) has a stronger influence on colon cancer risk. Fourth, the fact that there are 6 potential endpoints ( 3 dietary patterns and 2 racial groups) increases the likelihood of a positive finding. Finally, although we controlled for a wide range of potential confounding factors, the possibility for residual confounding remains. Prospective investigations are needed to obviate these limitations.

In conclusion, in this study of dietary patterns and colon cancer risk in Whites and African Americans in North Carolina, we identified 3 meaningful intake patterns. Only the fruitvegetable pattern was inversely associated with colon cancer risk in Whites but not in African Americans. The metropolitan pattern correlated with a nonsignificant $30 \%$ reduction in risk in both racial groups after control for education, but there were no associations of the Western-Southern pattern with colon cancer risk. The findings from this study may provide an explanation for some of the racial differences in colon cancer incidence and underscore the value of examining diet and cancer associations in different population subgroups.

\section{ACKNOWLEDGMENTS}

This research was funded by the following grants from the National Institutes of Health: Grant numbers K22 CA96556, R01 CA 66635, and P30 DK 34987.

\section{REFERENCES}

1. American Cancer Society. Cancer facts and figures. 2007 Available at http://www.cancer.org/ downloads/STT/CAFF2007PWSecured.pdf. 
2. Parkin DM, Pisani P, Ferlay J. Global cancer statistics. CA Cancer J Clin. 1999; 49:33-64. [PubMed: 10200776]

3. Surveillance, Epidemiology, and End Results (SEER). [Accessed November 8, 2007] Available at www.seer.cancer.gov.

4. Jemal A, Siegal R, Ward E, Murray T, Xu J, et al. Cancer statistics. CA Cancer J Clin. 2007; 57:4366. 2007. [PubMed: 17237035]

5. Polite BN, Dignam JJ, Olopade OI. Colorectal cancer and race: understanding the differences in outcomes between African Americans and whites. Med Clin North Am. 2005; 89:771-793. [PubMed: 15925649]

6. Martinez ME. Primary prevention of colorectal cancer: lifestyle, nutrition, exercise. Recent Results Cancer Res. 2005; 166:177-211. [PubMed: 15648191]

7. Giovannucci E. Modifiable risk factors for colon cancer. Gastroenterol Clin North Am. 2002; 31:925-943. [PubMed: 12489270]

8. Carethers JM. Racial and ethnic factors in the genetic pathogenesis of colorectal cancer. J Assoc Acad Minor Phys. 1999; 10:59-67. [PubMed: 10826011]

9. Doll R, Peto R. The causes of cancer: quantitative estimates of avoidable risks of cancer in the United States today. J Natl Cancer Inst. 1981; 66:1191-1308. [PubMed: 7017215]

10. Slattery ML. Diet, lifestyle, and colon cancer. Semin Gastrointest Dis. 2000; 11:142-146. [PubMed: 10950460]

11. Schatzkin A, Lanza E, Corle D, Lance P, Iber F, et al. Lack of effect of a low-fat, high-fiber diet on the recurrence of colorectal adenomas: Polyp Prevention Trial Study Group. N Engl J Med. 2000; 342:1149-1155. [PubMed: 10770979]

12. Kim YI. Vegetables, fruits, and colorectal cancer risk: what should we believe? Nutr Rev. 2001; 59:394-398. [PubMed: 11766910]

13. Tseng M. Dietary patterns and dietary makeovers. Public Health Nutr. 2004; 7:473-474. [PubMed: 15153251]

14. Hu FB. Dietary pattern analysis: a new direction in nutritional epidemiology. Curr Opin Lipidol. 2002; 13:3-9. [PubMed: 11790957]

15. Wacholder S, Weinberg CR. Flexible maximum likelihood methods for assessing joint effects in case-control studies with complex sampling. Biometrics. 1994; 50:350-357. [PubMed: 8068835]

16. Weinberg CR, Sandler DP. Randomized recruitment in case-control studies. Am J Epidemiol. 1991; 134:421-432. [PubMed: 1877602]

17. Aldrich TE, Vann D, Moorman PG, Newman B. Rapid reporting of cancer incidence in a population-based study of breast cancer: one constructive use of a central cancer registry. Breast Cancer Res Treat. 1995; 35:61-64. [PubMed: 7612905]

18. Satia-Abouta J, Galanko JA, Potter JD, Ammerman A, Martin CF, et al. Associations of total energy and macronutrients with colon cancer risk in African Americans and Whites: results from the North Carolina colon cancer study. Am J Epidemiol. 2003; 158:951-962. [PubMed: 14607803]

19. Gerber AM, James SA, Ammerman AS, Keenan NL, Garrett JM, et al. Socioeconomic status and electrolyte intake in black adults: the Pitt County Study. Am J Public Health. 1991; 81:1608-1612. [PubMed: 1746658]

20. Block G, Hartman AM, Dresser CM, Carroll MD, Gannon J, et al. A data-based approach to diet questionnaire design and testing. Am J Epidemiol. 1986; 124:453-469. [PubMed: 3740045]

21. Kleinbaum, DG.; Kupper, LL.; Muller, KE. Applied Regression Analysis and Other Multivariable Methods. 2nd ed. Belmont, CA: Duxbury Press; 1988.

22. Kline, P. An Easy Guide to Factor Analysis. New York: Routledge; 1994.

23. Cronbach LJ. Coefficient alpha and the internal structure of tests. Psy-chometrika. 1951; 16:297334.

24. Nunnally, J. Psychometric Theory. New York: McGraw-Hill; 1978.

25. Clinical guidelines on the identification, evaluation, and treatment of overweight and obesity in adults: executive summary. Expert Panel on the Identification, Evaluation, and Treatment of Overweight in Adults. Am J Clin Nutr. 1998; 68:899-917. [PubMed: 9771869] 
26. Blair SN, Haskell WL, Ho P, Paffenbarger RS Jr, Vranizan M, et al. Assessment of habitual physical activity by a seven-day recall in a community survey and controlled experiments. Am $\mathrm{J}$ Epidemiol. 1985; 122:794-804. [PubMed: 3876763]

27. Richardson MT, Ainsworth BE, Jacobs DR, Leon AS. Validation of the Stanford 7-day recall to assess habitual physical activity. Am J Epidemiol. 2001; 11:145-153.

28. Willett WC, Howe GR, Kushi LH. Adjustment for total energy intake in epidemiologic studies. Am J Clin Nutr. 1997; 65(Suppl):1220-1228.

29. Wu K, Hu FB, Fuchs C, Rimm EB, Willett WC, et al. Dietary patterns and risk of colon cancer and adenoma in a cohort of men (United States). Cancer Causes Control. 2004; 15:853-862. [PubMed: 15577287]

30. Slattery ML, Boucher KM, Caan BJ, Potter JD, Ma KN. Eating patterns and risk of colon cancer. Am J Epidemiol. 1998; 148:4-16. [PubMed: 9663397]

31. Fung T, Hu FB, Fuchs C, Giovannucci E, Hunter DJ, et al. Major dietary patterns and the risk of colorectal cancer in women. Arch Intern Med. 2003; 163:309-314. [PubMed: 12578511]

32. Terry P, Hu FB, Hansen H, Wolk A. Prospective study of major dietary patterns and colorectal cancer risk in women. Am J Epidemiol. 2001; 154:1143-1149. [PubMed: 11744520]

33. Huang MH, Schocken M, Block G, Sowers M, Gold E, et al. Variation in nutrient intakes by ethnicity: results from the Study of Women's Health Across the Nation (SWAN). Menopause. 2002; 9:309-319. [PubMed: 12218719]

34. Bialostosky K, Wright JD, Kennedy-Stephenson J, McDowell M, Johnson CL. Dietary intake of macronutrients, micronutrients, and other dietary constituents: United States 1988-94. Vital Health Stat. 2002; 11:1-158.

35. Polednak AP. Secular trend in U.S. black-white disparities in selected alcohol-related cancer incidence rates. Alcohol Alcohol. 2007; 42:125-130. [PubMed: 17255152]

36. Deshmukh-Taskar P, Nicklas TA, Yang S-J, Berenson GS. Does food group consumption vary by differences in socioeconomic, demographic, and lifestyle factors in young adults?: the Bogalusa Heart Study. J Am Diet Assoc. 2007; 107:223-234. [PubMed: 17258958]

37. Dixon LB, Balder HF, Virtanen MJ, Rashidkhani B, Männistö S, et al. Dietary patterns associated with colon and rectal cancer: results from the Dietary Patterns and Cancer (DIETSCAN) Project. Am J Clin Nutr. 2004; 80:1003-1011. [PubMed: 15447912]

38. Kim MK, Sasaki S, Otani T, Tsugane S. Japan Public Health Center-based Prospective Study Group: Dietary patterns and subsequent colorectal cancer risk by subsite: a prospective cohort study. Int J Cancer. 2005; 115:790-798. [PubMed: 15704172]

39. Satia-Abouta J, Galanko J, Martin CF, Ammerman A, Sander RS. Food groups and colon cancer risk in African Americans and Caucasians. Int J Cancer. 2004; 109:728-736. [PubMed: 14999782]

40. Armstrong, BK.; White, E.; Saracci, R. Principles of Exposure Measurement in Epidemiology. New York: Oxford University Press; 1994.

41. Palli D, Russo A, Ottini L, Masala G, Saieva C, et al. Red meat, family history, and increased risk of gastric cancer with microsatellite instability. Cancer Res. 2001; 61:5415-5419. [PubMed: 11454685]

42. Moorman PG, Newman B, Millikan RC, Tse CK, Sandler DP. Participation rates in a case-control study: the impact of age, race, and race of interviewer. Ann Epidemiol. 1999; 9:188-195. [PubMed: 10192651]

43. Slattery ML, Edwards SL, Caan BJ, Kerber RA, Potter JD. Response rates among control subjects in case-control studies. Ann Epidemiol. 1995; 5:245-249. [PubMed: 7606315]

44. Willett, W. Nutritional Epidemiology. 2nd ed. New York: Oxford University Press; 1998.

45. Subar AF, Kipnis V, Troiano RP, Midthune D, Schoeller DA, et al. Using intake biomarkers to evaluate the extent of dietary misreporting in a large sample of adults: the OPEN study. Am J Epidemiol. 2003; 158:1-13. [PubMed: 12835280]

46. Kipnis V, Midthune D, Freedman L, Bingham S, Day NE, et al. Bias in dietary-report instruments and its implications for nutritional epidemiology. Public Health Nutr. 2002; 5:915-923. [PubMed: 12633516] 
47. Kristal AR, Peters U, Potter JD. Is it time to abandon the food frequency questionnaire? Cancer Epidemiol Biomarkers Prev. 2005; 14:2826-2828. [PubMed: 16364996] 


\section{TABLE 1}

Descriptive characteristics of participants in the North Carolina Colon Cancer Study by race and case-control status $^{a}$

\begin{tabular}{|c|c|c|c|c|}
\hline \multirow[b]{2}{*}{ Participant Characteristic } & \multicolumn{2}{|c|}{ Whites } & \multicolumn{2}{|c|}{ African Americans } \\
\hline & $\begin{array}{r}\text { Cases } \\
(N=346)\end{array}$ & $\begin{array}{l}\text { Controls } \\
(N=610)\end{array}$ & $\begin{array}{r}\text { Cases } \\
(N=290)\end{array}$ & $\begin{array}{r}\text { Controls } \\
(N=432)\end{array}$ \\
\hline Mean $( \pm \mathrm{SD})$ age $(\mathrm{yr})$ & $65.0(9.7)$ & $66.1(9.4)$ & $61.9(10.3)^{* *}$ & $65.9(9.7)$ \\
\hline Female $(\%)$ & $153(44)$ & $280(46)$ & $152(52)$ & $247(57)$ \\
\hline \multicolumn{5}{|l|}{ Level of education (\%) } \\
\hline SHigh school & $196(57)$ & $297(49)$ & $209(72)$ & $301(70)$ \\
\hline Some college & $70(20)$ & $150(25)$ & $53(18)$ & $74(17)$ \\
\hline College graduate/advanced degree & $78(23)$ & $162(27)$ & $28(10)$ & $56(13)$ \\
\hline Mean $\left( \pm\right.$ SD) BMI $\left(\mathrm{kg} / \mathrm{m}^{2}\right)$ current & $27.3(5.7)$ & $27.6(5.4)$ & $28.8(6.5)$ & $29.7(7.0)$ \\
\hline \multicolumn{5}{|l|}{ BMI status current (\%) } \\
\hline $18.0-24.9$ & $123(36)$ & $187(31)$ & $74(26)$ & $102(24)$ \\
\hline $25.0-29.9$ & $123(36)$ & $259(43)$ & $110(39)$ & $142(33)$ \\
\hline$\geq 30.0$ & $95(28)$ & $152(25)$ & $101(35)$ & $181(43)$ \\
\hline Mean $( \pm \mathrm{SD}) \mathrm{BMI}\left(\mathrm{kg} / \mathrm{m}^{2}\right) 1 \mathrm{yr}$ ago & $28.4(5.6)^{*}$ & $27.6(5.2)$ & $30.5(6.7)$ & $28.7(6.4)$ \\
\hline \multicolumn{5}{|l|}{ BMI status 1 yr ago (\%) } \\
\hline $18.0-24.9$ & $95(28)$ & $184(31)$ & $42(15)$ & $85(21)$ \\
\hline $25.0-29.9$ & $140(42)$ & $251(42)$ & $116(42)$ & $151(37)$ \\
\hline$\geq 30.0$ & $101(30)$ & $156(26)$ & $121(43)$ & $171(42)$ \\
\hline \multicolumn{5}{|l|}{ Smoking history $(\%)$} \\
\hline Never & $117(34)^{*}$ & $246(40)$ & $135(47)$ & $198(46)$ \\
\hline Former & $180(52)$ & 267 (44) & $95(33)$ & $144(33)$ \\
\hline Current & $46(13)$ & $96(16)$ & $58(20)$ & $90(21)$ \\
\hline Mean ( \pm SD) physical activity level (MET min/day) & $2,261(563)$ & $2,208(501)$ & $2,242(591)^{*}$ & $2,149(517)$ \\
\hline Family history of colon cancer (\%) & $76(22)^{* *}$ & $57(9)$ & $51(18)^{* *}$ & $45(10)$ \\
\hline \multicolumn{5}{|l|}{ NSAID use over past 5 yr (\%) } \\
\hline Never & $38(11)^{* *}$ & $43(7)$ & $33(11)^{* *}$ & $31(7)$ \\
\hline Occasionally & $129(38)$ & $174(29)$ & $125(43)$ & $139(32)$ \\
\hline Regularly & $177(51)$ & $392(64)$ & $132(46)$ & $262(61)$ \\
\hline Vitamin/mineral supplement use (\%) & $156(45)^{* *}$ & $328(55)$ & $94(33)$ & $166(39)$ \\
\hline \multicolumn{5}{|l|}{ Residence } \\
\hline Urban (\%) & $250(72)$ & $476(78)$ & $212(73)$ & $335(78)$ \\
\hline Rural (\%) & $95(28)$ & $134(22)$ & $78(27)$ & $97(22)$ \\
\hline
\end{tabular}

\footnotetext{
${ }^{a}$ Abbreviations are as follows: BMI, body mass index; MET, metabolic equivalent task; NSAID, nonsteroidal anti-inflammatory drug. ${ }^{*} P<0.01$.

$\stackrel{* *}{P}<<0.05$
} 


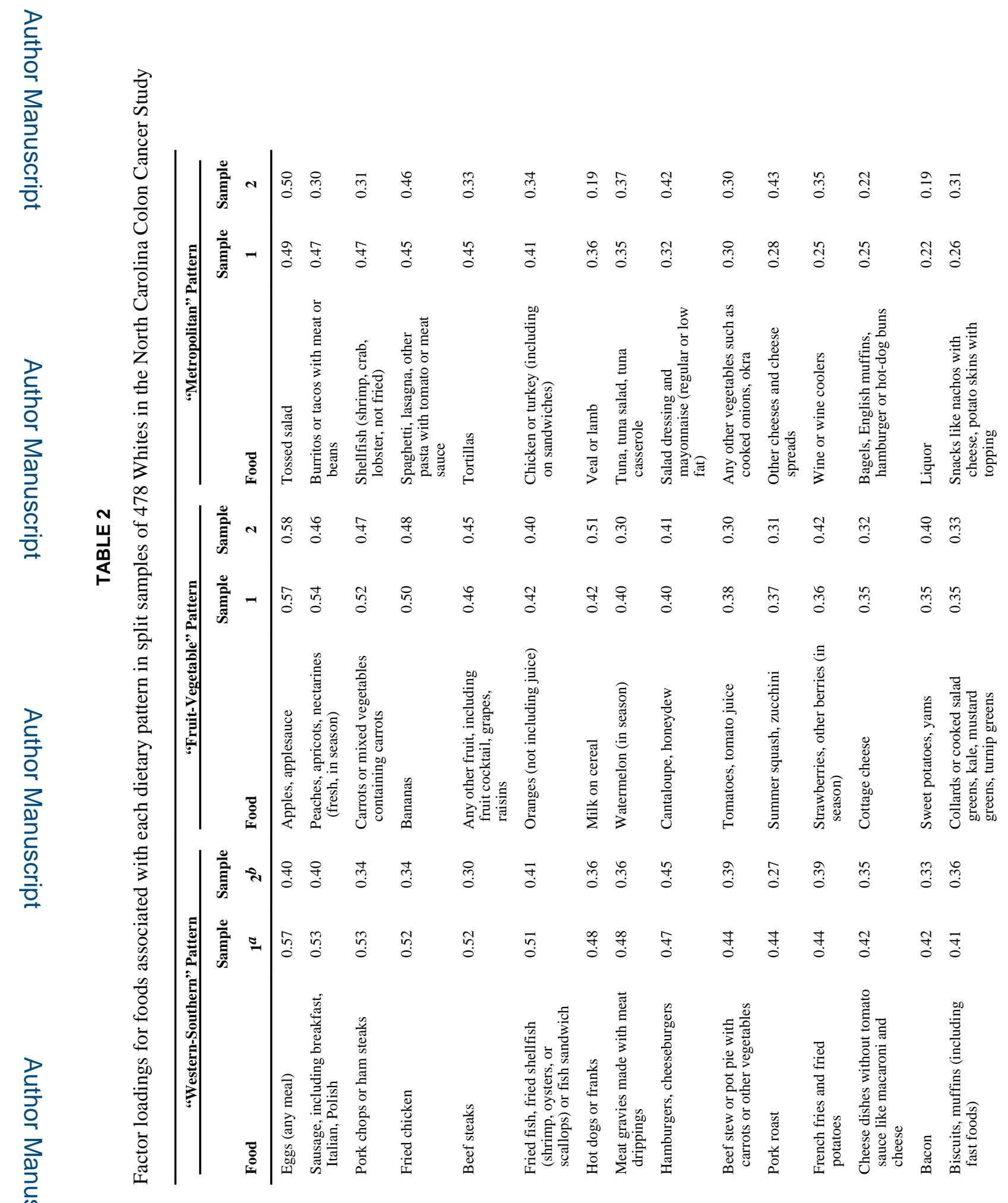

Nutr Cancer. Author manuscript; available in PMC 2015 April 13. 


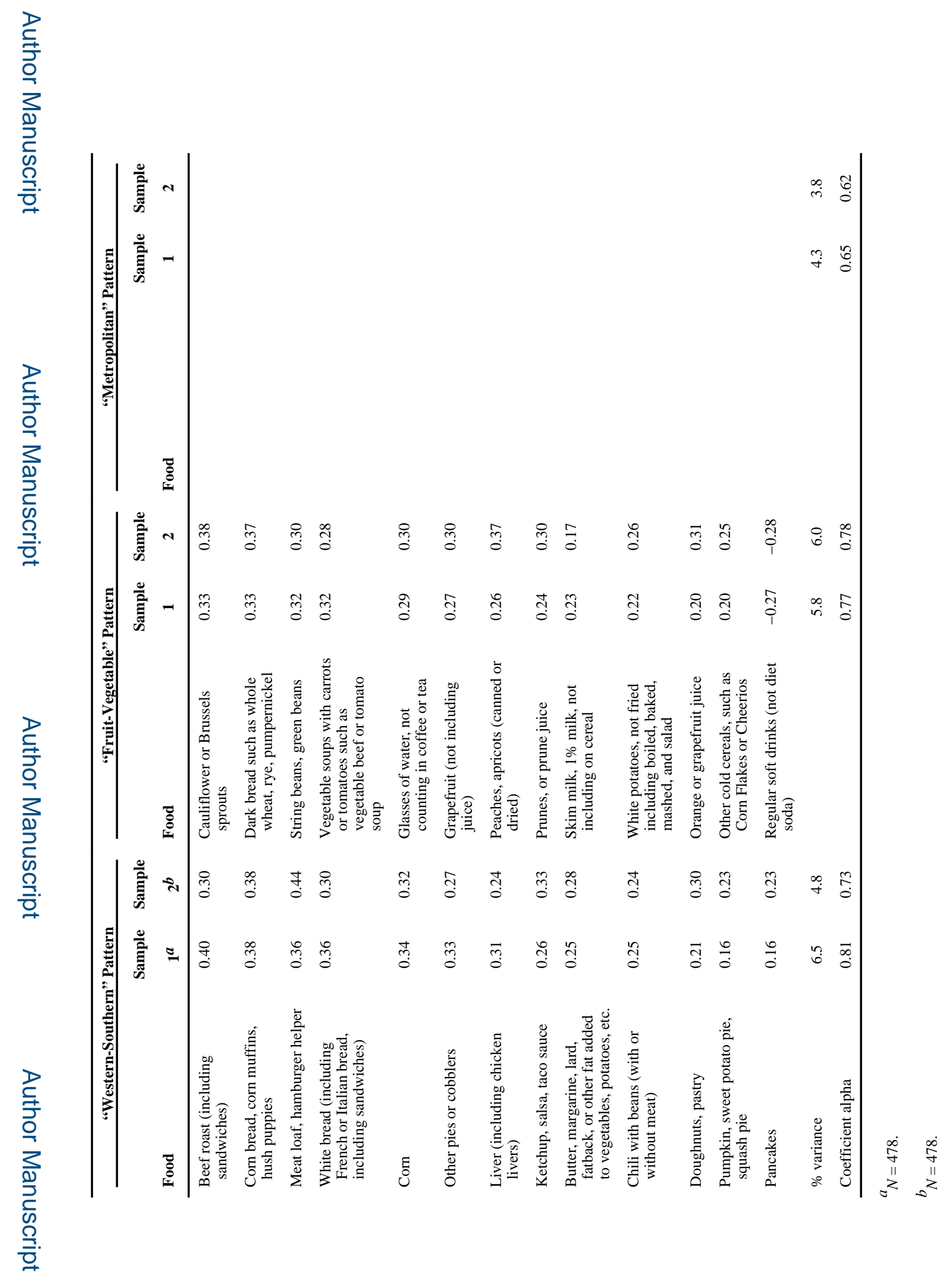

Nutr Cancer. Author manuscript; available in PMC 2015 April 13. 


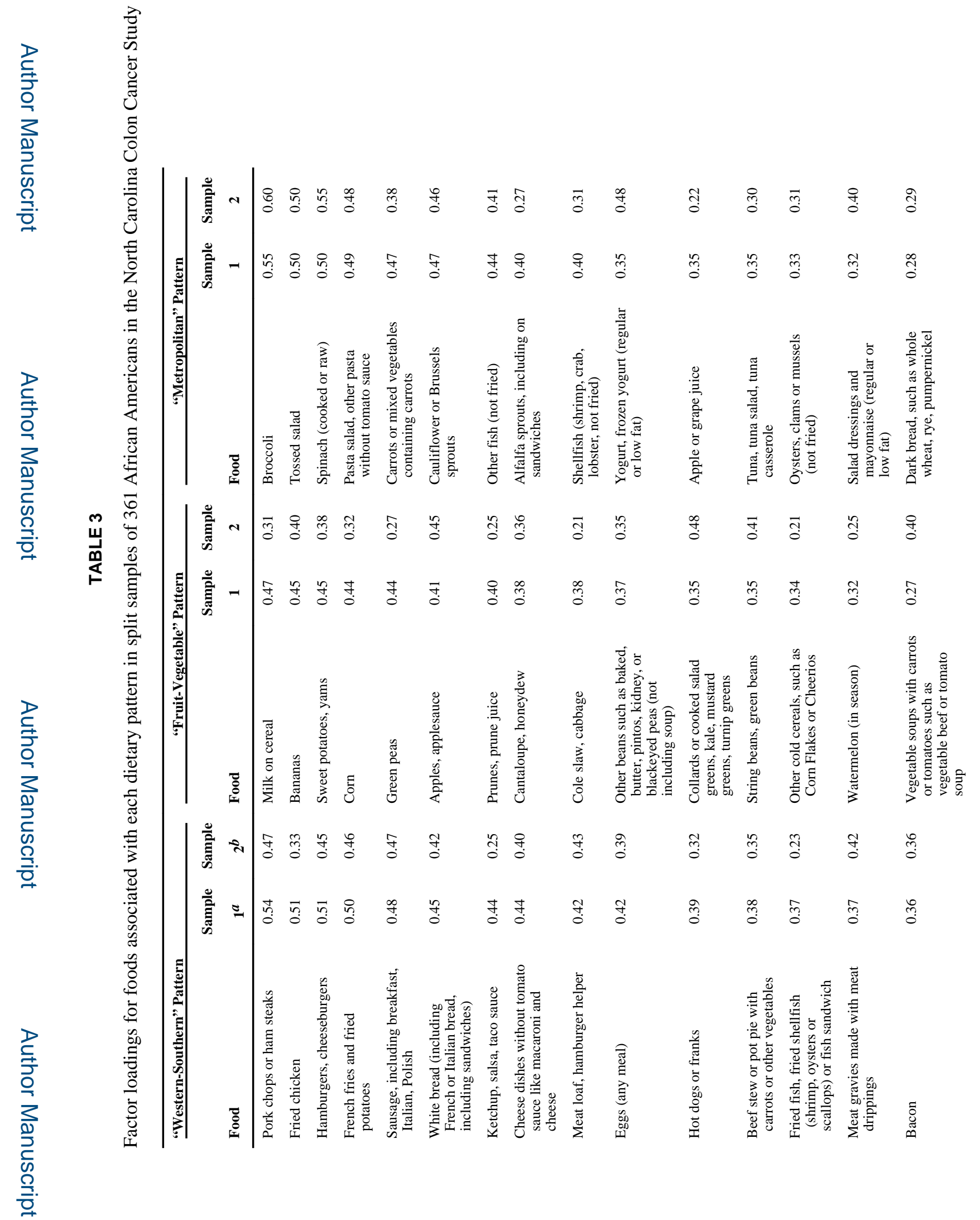

Nutr Cancer. Author manuscript; available in PMC 2015 April 13. 


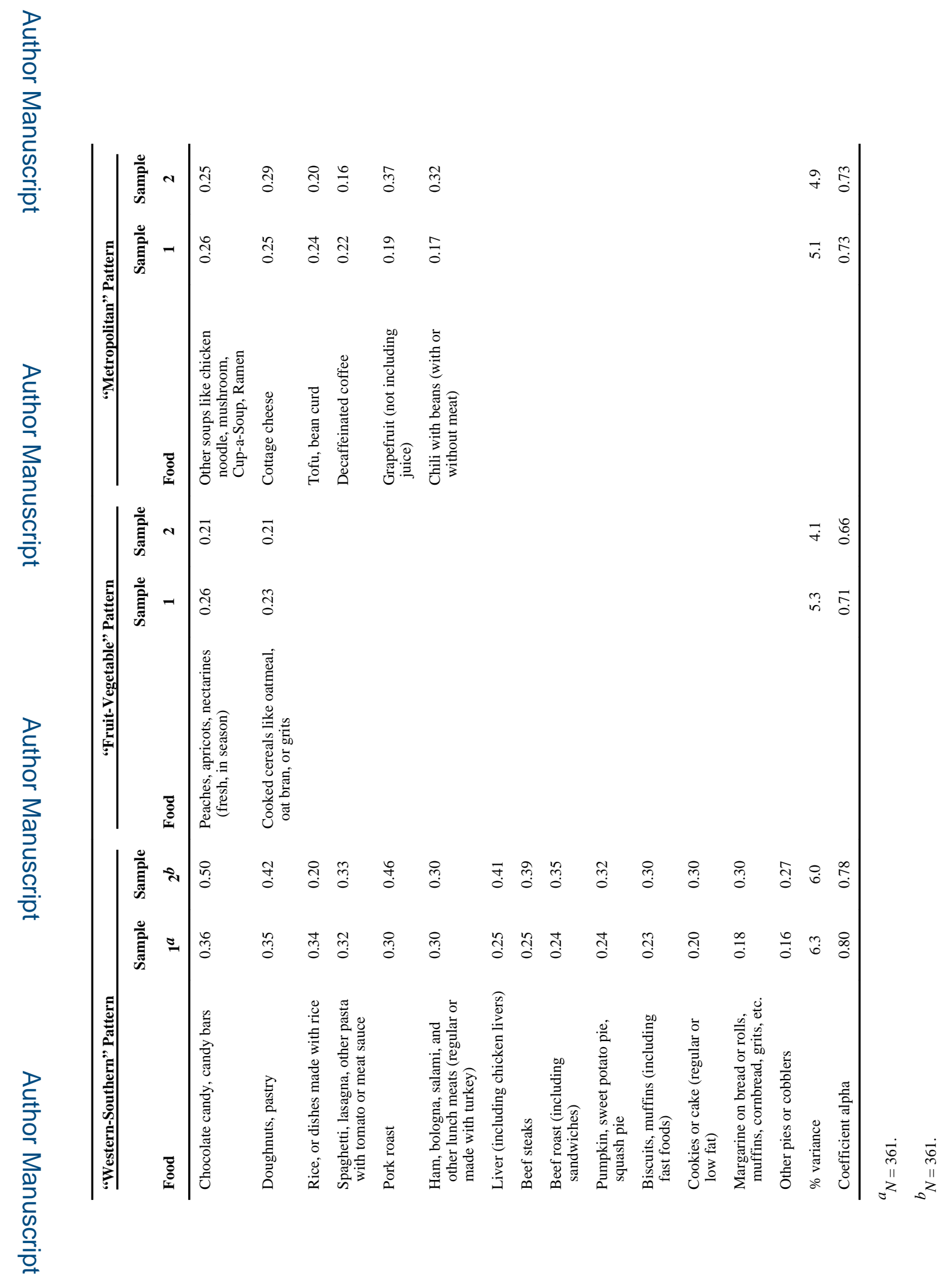

Nutr Cancer. Author manuscript; available in PMC 2015 April 13. 


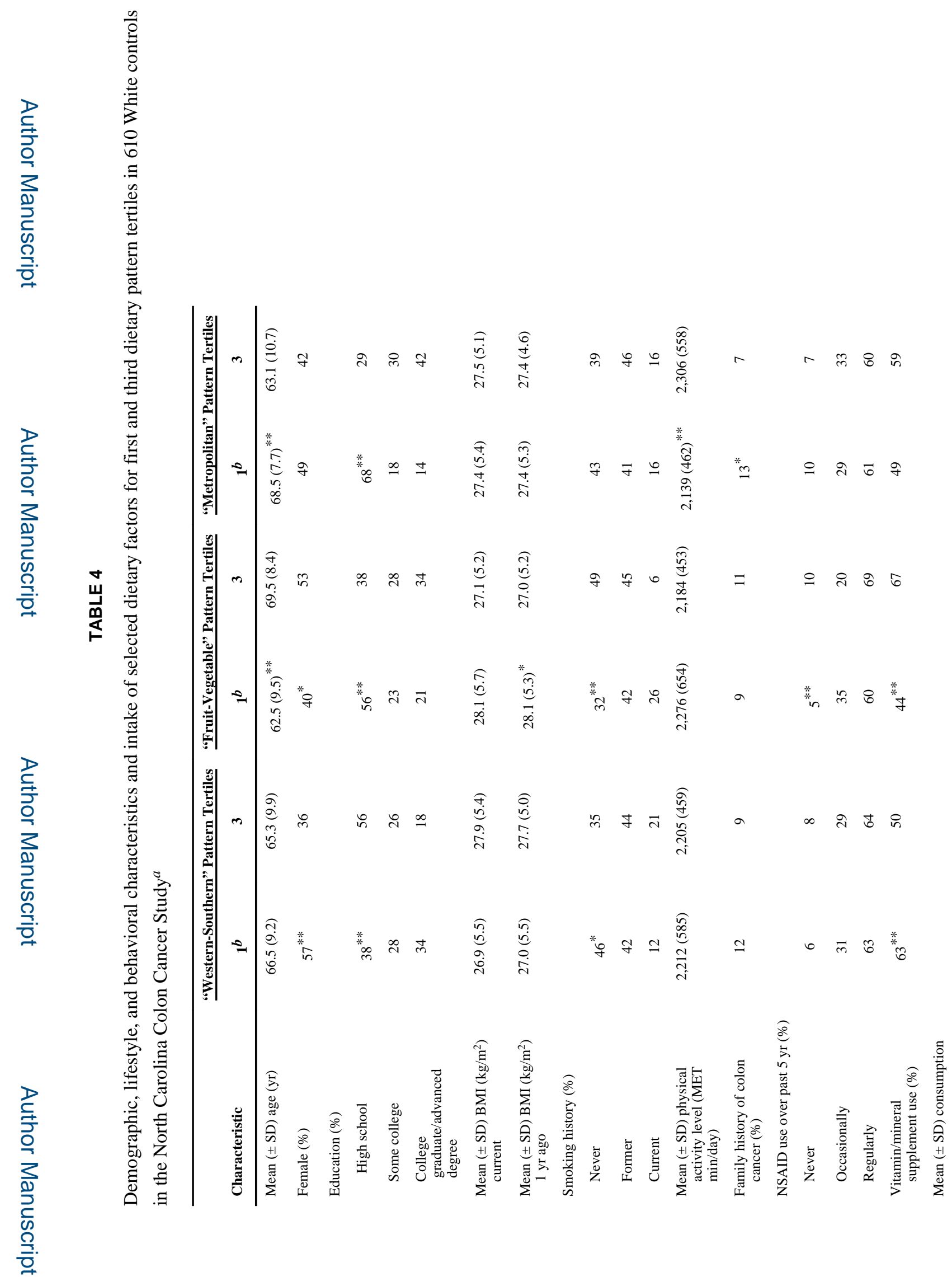

Nutr Cancer. Author manuscript; available in PMC 2015 April 13. 


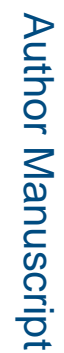

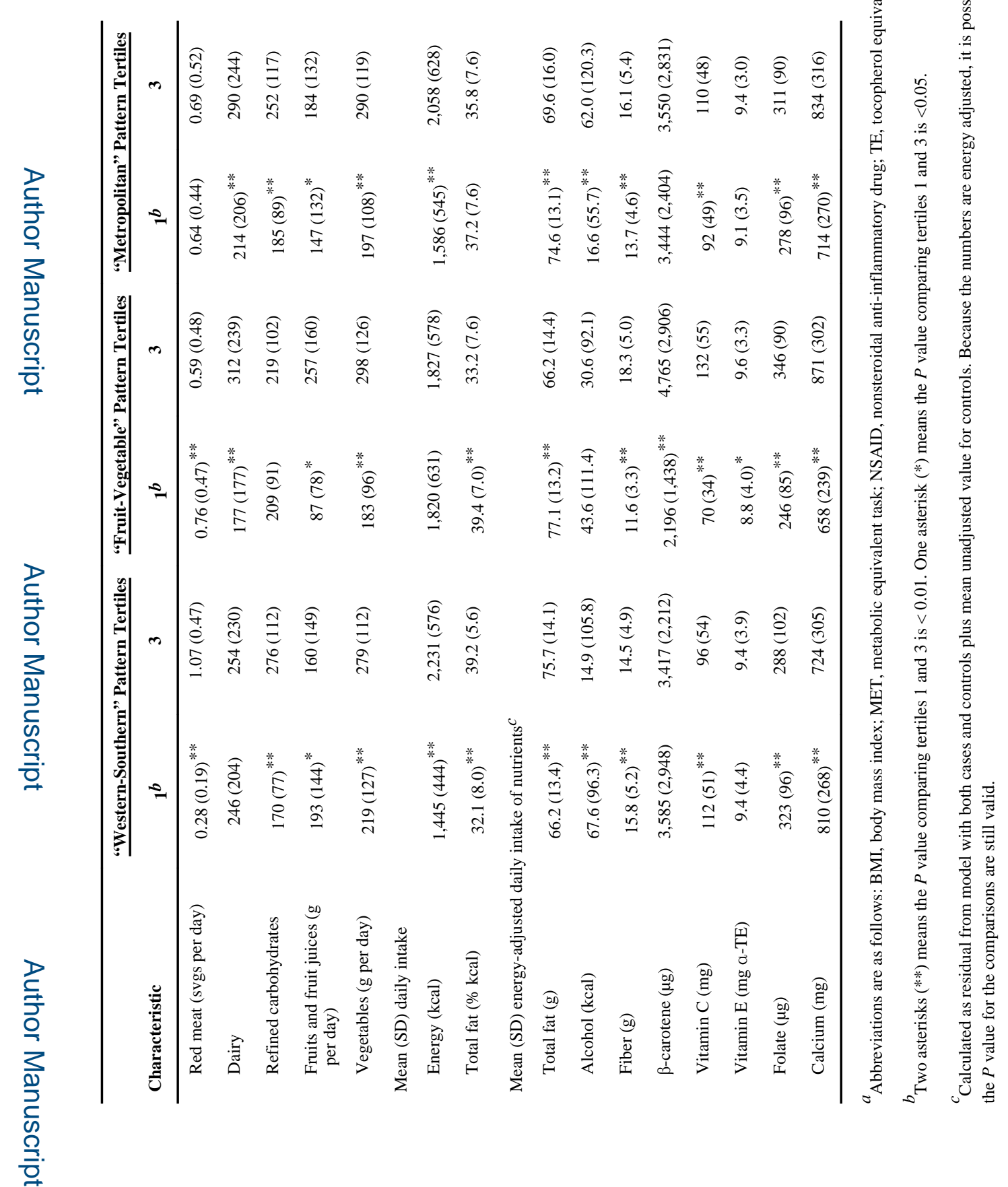

Nutr Cancer. Author manuscript; available in PMC 2015 April 13. 


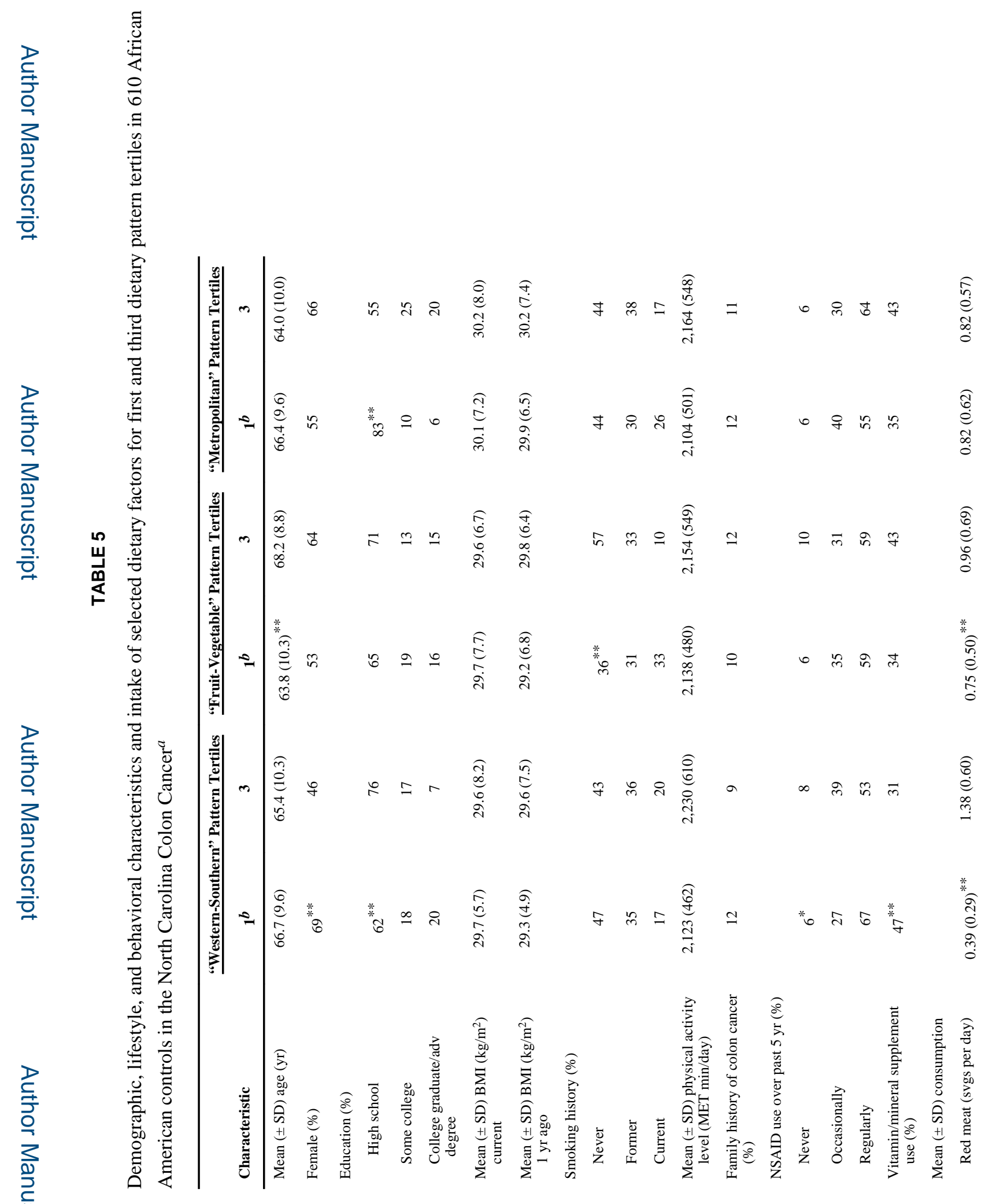

Nutr Cancer. Author manuscript; available in PMC 2015 April 13. 


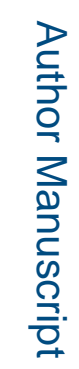

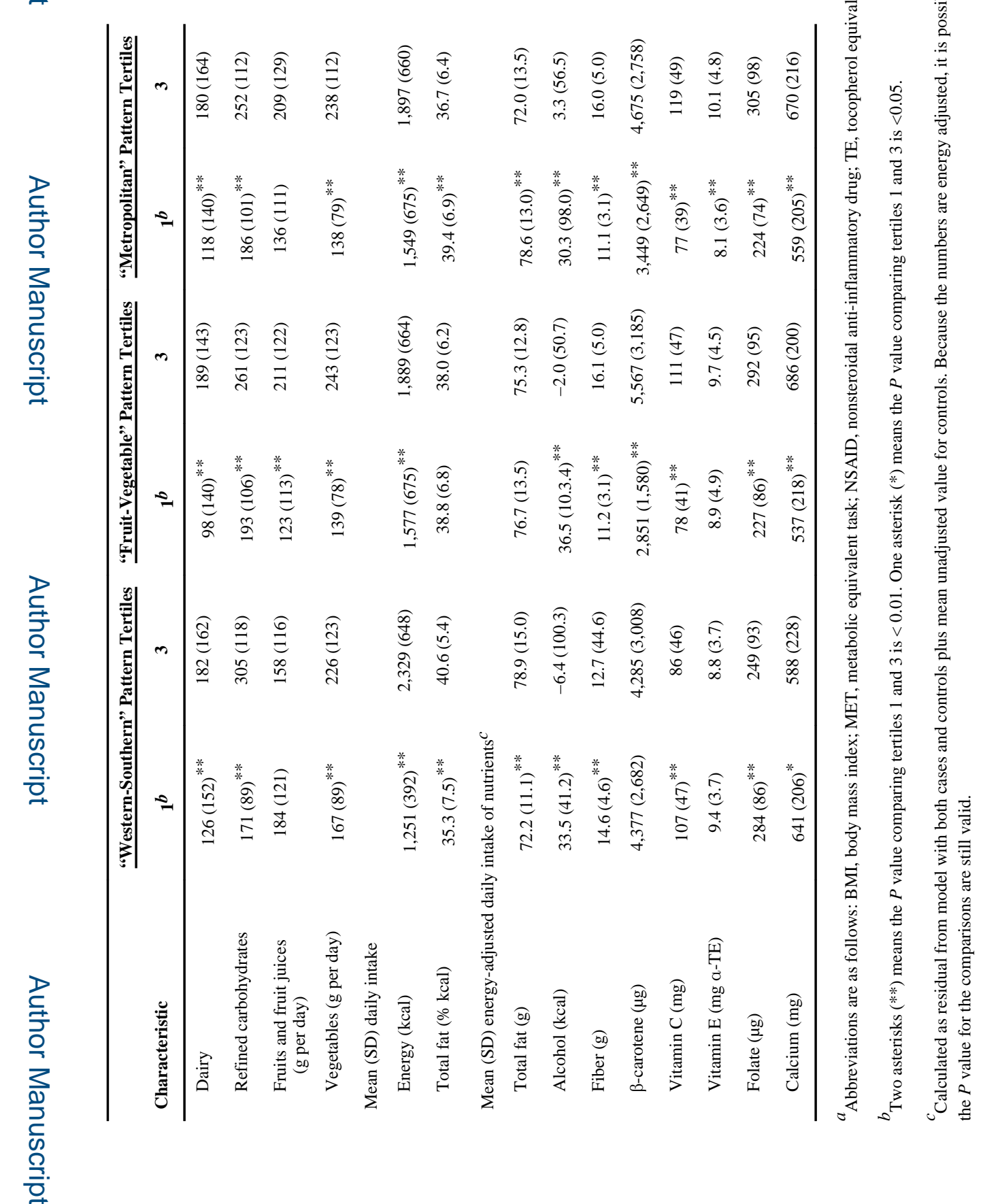

Nutr Cancer. Author manuscript; available in PMC 2015 April 13. 


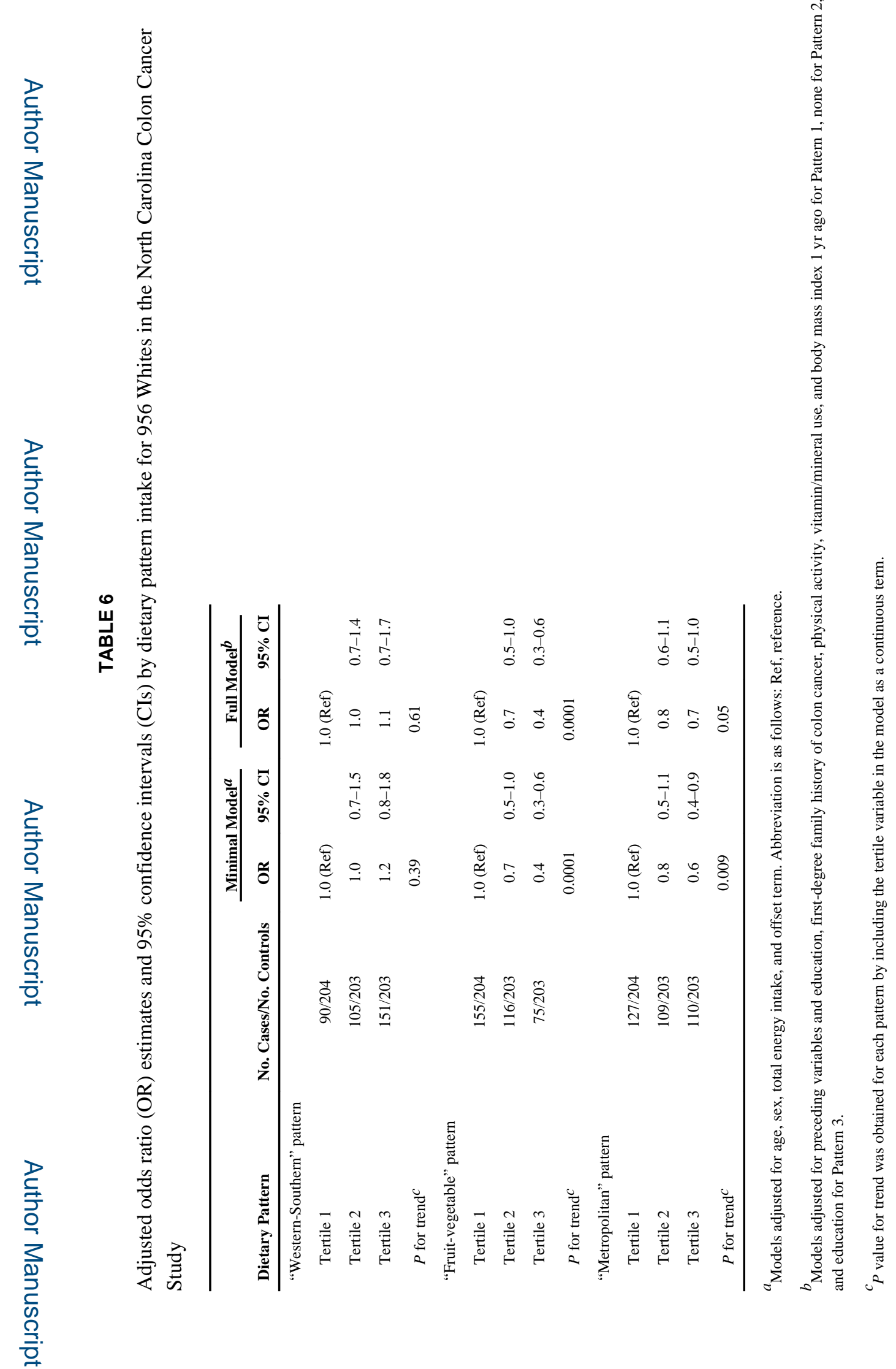

Nutr Cancer. Author manuscript; available in PMC 2015 April 13. 


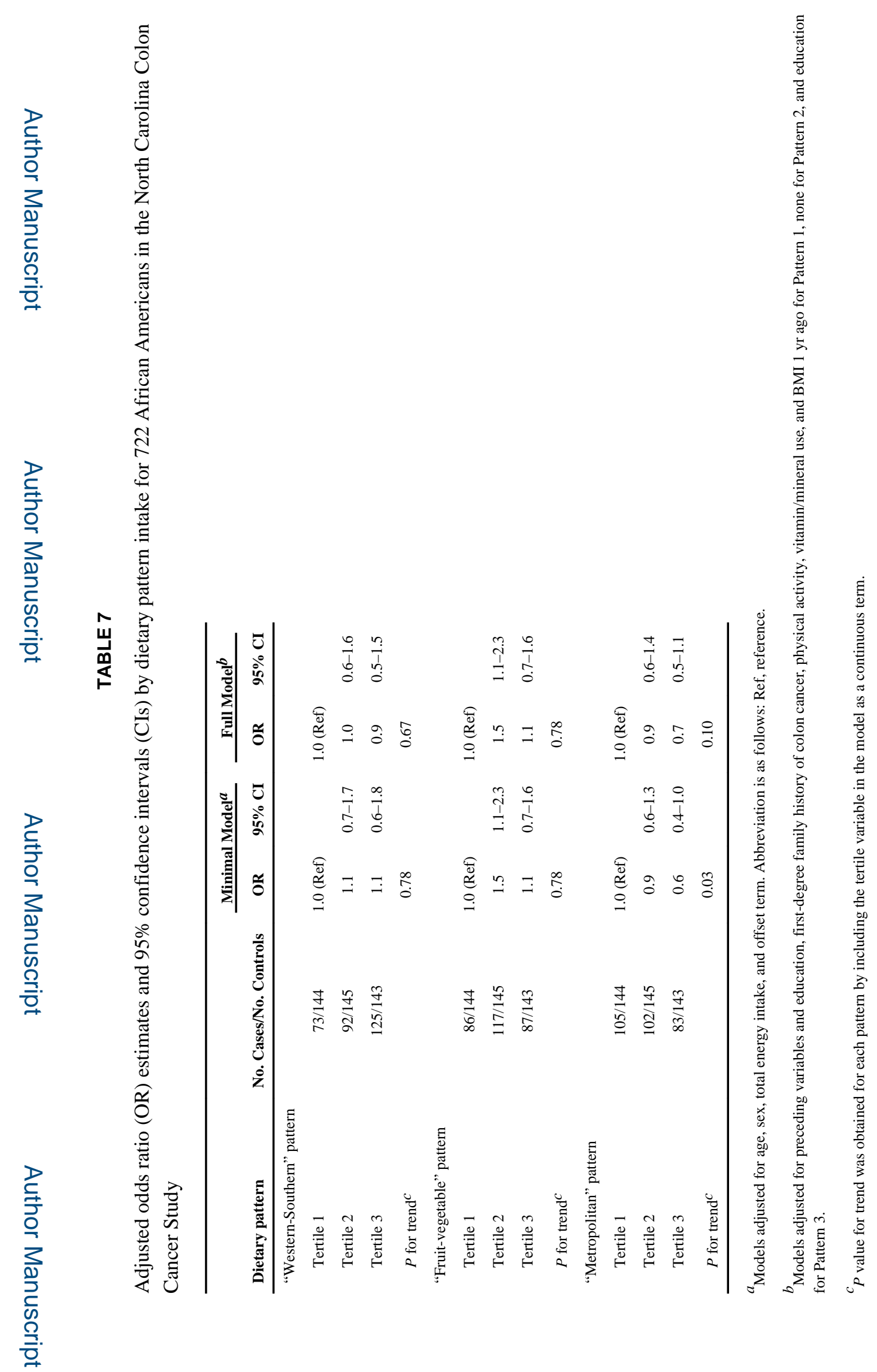

Nutr Cancer. Author manuscript; available in PMC 2015 April 13. 